\title{
Analysis On The Future Development Of Cloud Education
}

\author{
Liucheng Zhang ${ }^{1, \text { a }}$ \\ 1The practice teaching management center,Harbin University of Commerce,Harbin,China \\ a'zhangliucheng@126.com
}

Keywords: cloud education ;cloud computing ;development prospects

\begin{abstract}
This This paper begins with an overview of the cloud education historical basis and composition, and the cloud education development present situation has carried on the analysis and explore our country in the field of education of cloud computing applications and the ways and our cloud education market, analysis of the cloud calculation in the construction and development of application in the field of education, analysis of the education cloud the prospects for future development.
\end{abstract}

\section{Historical basis of cloud Education}

China's network education began in 1994, the national implementation of the education and scientific research network demonstration project. Since the beginning of twenty-first Century, the rapid development of computer and Internet has brought great uncertainty to the future of education reform. In the cloud computing on the basis of birth and education resource sharing platform for urgent degree under the environment of cloud education came into being.

In the course of history, the core problem of the construction of cloud education is the lack of both the computer and the Internet. From some kind of meaning said that computers and the Internet in the developing and mature. At the same time, they are phagocytosis of the bottomless pit of education funds, how to put the limited education funds on the cutting edge of the development of computer and network teaching, countries and education should first consider the problem.

\section{Development of cloud Education}

Development of cloud Education.In recent years, the rapid development of network technology, not only affects the process of education reform in China, but also affects the process of education reform in the world.

Over the past ten years, the level of basic education has been greatly improved, and the construction of software and hardware has made great progress. The object of education is no longer limited to the students, education resources to accelerate the transformation of the virtual, global, interactive and open. As the mobile internet classroom, a wide range of learning resources and community, student-centered personalized teaching is to subvert the traditional fixed classroom, the fixed teacher and the fixed curriculum education. The integration of family, school and social education characteristics of social education informationization will gradually stepped on the stage, and it is able to resolve the economic differences caused by the "digital divide" and technical differences lead to the "information island", "knowledge change acceleration" and other problems.

However, universal platform for the development of education at the same time, some problems also gradually revealed. For example: (1)the network education platform function generalization, in the existing network education platform, widespread platform on the extension of the function, the module function. (2)We ignore the educational function of the learner's attention platform, resulting in repeated construction of resources.

Lack of cloud education development.In all levels of education information management system, there are the following problems: 
The user is widely distributed, the basic data is not uniform, each system is independent of each other, the information is relatively closed, the sharing mechanism has not been established, the lack of coordination between the various systems, basically in the "information island" state.

The current situation of the school information service, only a small part of the information application of better schools with school information service platform. Administrative affairs management, resource management, teaching management application system mostly from different companies to buy, involved the platform in the standard, ease of use, security and other aspects of the different, can not meet the demand of data acquisition, data exchange, resource sharing, information exchange. Isolated from each other between the system, a system has a login account, it is not convenient for teachers to use.

For education resources storehouse construction present situation, in recent years, the education departments at all levels purchased all kinds of resource library, due to the lack of promotion and training, teachers of these resources know little, the overall efficiency in the use of less than ideal. Some of the high quality resources for teachers' personal quality are mostly in the form of documents. The mode of resource transmission mainly include email, QQ or file sharing. Due to the poor sharing, there are a lot of duplication of resources in the production of labor, has not yet formed a complete network of educational resources.

\section{The future development trend of cloud Education}

After many years of development, the public has seen the cloud technology is still limited to the cloud disk. Although we look forward to the future of the cloud, but very few people can accurately describe the future of cloud education can bring us. In today's society, many of the Internet itself is also extended to the cloud confused, but constantly launched their own cloud products. After carefully after resolution can be seen similar functional types of these cloud products, but did not grasp the product of historical development trend.

The development of China's cloud technology.In May 2012, the Ministry of industry and information communication industry released 《" 12th Five-Year "development plan》, will cloud computing positioning for building national information infrastructure, the key technologies and the direction of integration and innovation. In September 2012, the Ministry of science and technology released the first ministerial level special planning 《cloud computing technology development China "12th Five-Year "special plan》, is of great significance for speeding up the cloud computing technology innovation and industrial development.

Significant progress has been achieved in China based cloud computing products and operating system technology. In the cloud computing infrastructure products, China has exceeded EB storage system software and hardware technology and support server system technology to deal with concurrent billion level tasks. At the same time, the Internet enterprise computing operating system in large-scale cloud breakthroughs, including elastic computing systems, distributed computing systems, structured data storage system and open storage system etc.

In 2013, the Ministry of industry and information technology is working on the development of the comprehensive standard of cloud computing. On the basis of combing the existing information technology standards to develop new cloud computing standards, revise existing standards, build a cloud computing standard system to meet the needs of the industry management and users.

China Cloud education market analysis.

Analysis of political factors.Domestic cloud computing services Related Companies is expected to get the strong support of national policy. May 22, 2014, the state Internet Information Office said that China is about to launch a network security review system, the system is designed to review the security and controllability of information technology products. It is worth noting that, cloud computing services will also become the subject of review, the domestic cloud computing services Related Companies is expected to receive strong support from national policy.

Analysis of economic factors.Cloud education by means of resource management, virtualization, green computing reduce energy consumption, reduce operation and maintenance costs; by improving 
the management efficiency and reduce the manual maintenance and manpower, reduce manpower cost; large commercial cloud providers have more mature, more professional experience, provide the service more safe and reliable; data center and the expansion of the scale of sharing mechanism can reduce the heterogeneous and increase the use of resources, increase the supplier purchasing power. Analysis of social factors.In today's society, the demand for high quality education is huge, and the combination of cloud computing and education is in line with the trend of social development. People's understanding of cloud computing has been improved, which provides a good social background for the development of cloud education.

Consumer factor analysis. Consumer motivation is to meet the needs of people, there are three major categories, survival, development and enjoyment, for consumers at different levels of demand to guide and meet their needs, in order to win customers. Because consumer behavior can be infected, so the consumption of relevant groups of individuals have an important impact on the individual. With the increasing development of Internet and cloud computing, cloud education is irreversible.

In summary, judged according to the domestic market environment and industry maturity degree, cloud infrastructure operation will become the "cloud computing" is the core of the development of industrial chain, and education cloud will in the joint efforts of all parties has become more mature and stable.

Future development trend of cloud Education.Today, "cloud computing" will existing for the educators and the educated, all based on network service, network education in our country have a certain scale of development, despite the slow development trend, but remained rise. "The cloud service education" list with the development of the network, can be very long.

The cloud was still in the early stage, cloud education this set of cloud technology and education resources integration platform in development period, but as long as we break through the bottleneck of the development, future work will be much simpler, when the cloud platform education development is mature, users as long as the software is installed in the cloud server can be. As long as do the compatibility of a system, can be universal.

The represents the development direction of network education model of network education is based on pattern, network education and learning in the network environment, can maximize the play learner autonomy enthusiasm can individual learning, and collaborative learning, this kind of education mode of pay more attention to the learning needs of the individual. In the "cloud teaching network", can provide situational teaching of teacher-student interaction to provide unlimited great imagination and teaching scene; every student database in "the whole network teaching resource library cloud", all kinds of network key you can open at any time to read their own learning materials; " the cloud research network", each teacher will be available online to exchange teaching experience, to reform the latest information, published his own academic point of view; in the "cloud student evaluation" on the Internet, every student will because the comprehensive performance of their academic performance, learning performance, personal characteristics and be active network scientific and reasonable, and has the human vision of development of comprehensive evaluation; in the "cloud education employment counseling" network, there will be growth records and personal letter of each student with the record, the student and the employer can make interactive information at any time.

The cloud computing platform in the future, almost everyone will take a certain type of hybrid cloud platform, which has become represent the general trend. Most companies are related to the cloud, no matter what people are in the platform, the goal of the new cloud management solution is to control the cloud, mixed, public, private and even community clouds can be controlled. Cloud computing platform in the future to support hybrid deployment, data can be easily implemented in the private cloud and public cloud transfer between. So in the near future, cloud technology based on cloud education will permeate all aspects of society, in any environment can be used to learn the new cloud resources and knowledge. 


\section{Conclusions}

In today's information technology, cloud computing based education services platform has a bright future, has a broad market development, great potential. Education service platform based on cloud computing for the majority of users provides a comprehensive quality education platform, to realize the sharing of resources, and on the basis of Educational Metropolitan area network, in the construction of "the relative concentration of" ideas of education metropolitan area network application service planning. It uses advanced cloud technology (64 bit flexible structure) and education depth integration, innovative education model (collaborative education), to achieve the balance of education, for the fair education services. Education service platform based on cloud computing can not only solve the problem of data connectivity, eliminate information islands, to realize the resource integration and sharing, and flexibility to cope with the future development demand, also can according to the demand of the development and changes in the platform construction of rapid development of rich variety of education application, and to ensure that the application of organic unification, integrated innovation, the maximum benefit.

\section{Acknowledgements}

This work was financially supported by the Natural Social Science Foundation (15BJY017). National-level Project of College Student's Innovative and Entrepreneurial Training Program,Code of Project: 201510240001

\section{Reference:}

[1] Chen Kang, Zheng Weimin. Cloud computing system: examples and research status of [J] 《Journal of software》, 2009, 20 (5): 1337-1348

[2] Sun Mingjun. Analysis of the development status of cloud service industry [J] 《Internet world》, 2014 (8)

[3] Gao Yuan, College students' innovative entrepreneurial training plan of project process management research and exploration [J], Journal of laboratory science, 2013 (6), pp. 71-74.

[4] Yang Weizhi, Using the simulation system to cultivate students ability of enterprise management [J], Journal of laboratory research and exploration, 2013, no. 4, pp. 11-13.

[5] Zhang Li,Applied talents cultivation of innovative thinking mode exploration [J], China's higher education, 2012, (19) , pp.12-13

[6] Chen Yinping, Yin Long, College students' innovative entrepreneurial training plan to carry out the practice and exploration, in Harbin university of commerce, for example [J], Journal of new economy, 2014,(15) , pp. 41-54.

[7] Si Songmen, Zhuang Yale, Thinking about college students' innovative entrepreneurial training program [J], Journal of heilongjiang education (higher education research and evaluation), 2014, (7), pp. 31-33.

[8] Zhang Li. Exploration of innovative thinking mode of application oriented personnel training,.2012 (19).62-63 of higher education in China

[9] Zhang Li. Deepen the reform of practical teaching to enhance students' Entrepreneurship and innovation ability. Laboratory research and exploration.2010 (3) 